\title{
Anode-fall Voltages of Air Arcs Between Electrodes of Copper, Silver and Tungsten at Currents up to $1500 \mathrm{~A}$
}

\author{
Rei Hemmi* Member \\ Yasunobu Yokomizu* Member \\ Toshiro Matsumura* Member
}

\begin{abstract}
A method for estimating an anode-fall voltage of an arc discharge was developed. By using this method, the anode-fall voltages were evaluated for air arcs in atmosphere burning between the electrodes of copper, silver and tungsten. The anode-fall voltages $V_{\mathrm{a}}$ of air arcs proved to be about 1.2, 4.5 and $1.2 \mathrm{~V}$ for the copper, silver and tungsten electrodes respectively and were found to be almost independent of the ac half-wave current from 350 up to $1500 \mathrm{~A}_{\text {peak }}$. From the above results, the difference in the anode material seems to lead to the variation in the anode-fall voltage.
\end{abstract}

Keywords: air arcs, anode-fall voltage, erosion mass, cross-section of arc spot, energy balance equations

\section{Introduction}

Arc discharges, usually established between metal electrodes, are widely used for industrial applications such as circuit breakers and plasma torches. As is known, the anode and cathode fall regions of an arc form in the vicinity of the anode and cathode surfaces. Anodic and cathodic phenomena of the arc, e.g. erosion and temperature rise, seem to depend upon the amount of energy injected into the anode and cathode surfaces. This energy transport to the anode and cathode is governed by the voltage falls in the regions ${ }^{(1)}$. Therefore, it is important to find out the anode-fall and cathode-fall voltages.

Much effort has been spent on the measurement of the voltage drops in the anode and cathode fall regions $^{(1) \sim(6)}$. However, most of the measurements were restricted to dc arcs at low currents below a few hundred amperes. In addition, there were less reports on the anode-fall voltage than those on the cathode-fall voltage.

From the viewpoint of the above, we have developed a method for measuring the anode-fall $V_{\mathrm{a}}$ and the cathodefall $V_{\mathrm{c}}$ individually ${ }^{(7)}$. This method was applied to an air arc between silver electrodes to find out the anodefall and the cathode-fall voltages in a current range of 350 to $1200 \mathrm{~A}_{\text {peak }}{ }^{(7)}$. This method consists of three procedures as mentioned below. First, in the case of anode, the erosion mass $M_{\mathrm{a}}$ of an anode and the cross-section $S_{\mathrm{a}}$ of an anode spot were measured for an ac arc burning during half cycle. Secondly, the numerical calculations of energy balance equations on the anode were executed for different $V_{\mathrm{a}}$ and $S_{\mathrm{a}}$ to derive the dependence of $M_{\mathrm{a}}$ on $V_{\mathrm{a}}$ and $S_{\mathrm{a}}$. Lastly, comparison between the both results enables us to derive an anode-fall voltage.

\footnotetext{
* Department of Electrical Engineering, Nagoya University

Furo-cho, Chikusa-ku, Nagoya 464-8603
}

The above-mentioned method was applied to ac air arcs in atmosphere with electrodes of copper, silver and tungsten, used as the contact material in molded case circuit breakers or electro-magnetic switches, to find out the dependence of the anode-fall voltage on the anode material. The measurements of the anode-fall voltages for these materials were performed in a current range from 350 to $1500 \mathrm{~A}_{\text {peak }}$ to discuss the influence of the current on the anode-fall voltage.

2. Measurement of Erosion Mass and Cross-section of Anode Spot

2.1 Experimental Setup Fig. 1 illustrates the arc device and the current supply circuit. This arc device was installed in the atmosphere. In the arc device, an anode and a cathode discs of $5 \mathrm{~mm}$ in diameter and $1.5 \mathrm{~mm}$ in thickness were mounted. Copper, silver and tungsten were adopted as the electrode materials. The gap length between the electrodes was adjusted to be $5 \mathrm{~mm}$.

An ac current with a frequency of $50 \mathrm{~Hz}$ was supplied from a $1600 \mu \mathrm{F}$ capacitor bank through a $6.5 \mathrm{mH}$ reactor. Then an arc is ignited between electrodes by the blowout of the very small-gage wire of $0.05 \mathrm{~mm}$ in diameter. For the electrodes of copper and tungsten the copper wire was used, and for silver electrode the silver wire was used. The peak value of the ac current was adjusted in the range from 350 to $1500 \mathrm{~A}$. An auxiliary circuit breaker interrupted the ac current at the first current zero point. Fig. 2 indicates typical oscillograms of the ac current with a peak value of $1500 \mathrm{~A}$ and the corresponding arc voltage for an air arc between copper electrodes.

2.2 Erosion Mass of Anode For the first step of estimating the anode-fall voltage, we measured the erosion mass $M_{\mathrm{a}}$ of the anode. The difference in mass of the anode between before and after the arc discharge 


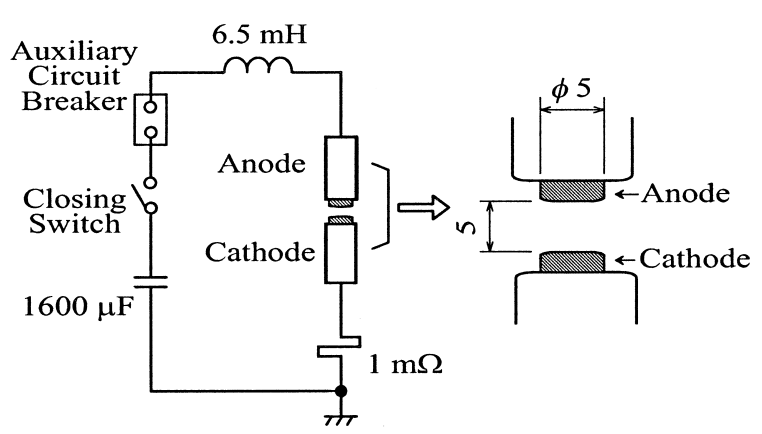

Fig. 1. Arc device and current supply circuit
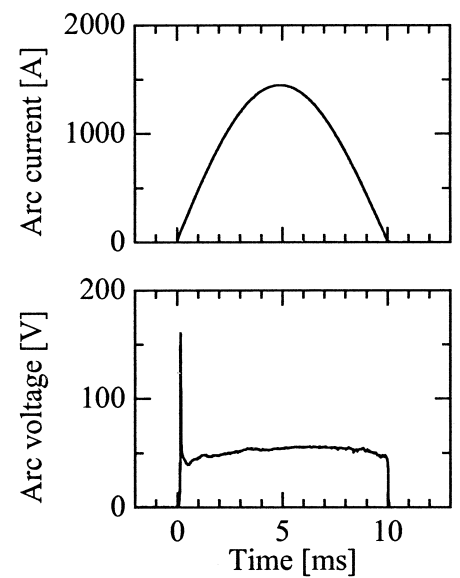

Fig. 2. Typical example of waveforms of arc current and arc voltage for copper electrode

was regarded as the erosion mass $M_{\mathrm{a}}$. The resolution of the balance used in the experiment is $0.01 \mathrm{mg}$.

The erosion mass was assumed to be the mass loss caused only by the evaporation, since the scatter of liquid metal from the anode was not observed in the experiment. In addition, There were very few deposited metal particles on the anode surface which was carried from the cathode surface by the arc jet. This fact was confirmed by the measurement of the erosion mass with the combinations of "copper anode-silver cathode" and "silver anode-copper cathode", and by the fluorescent X-ray analysis of the anode suface after the arc discharge $^{(8)}$. Furthermore, the effect of the blowout of the wire on the erosion mass can be neglected, as the mass of wire to ignite an arc is less than $0.003 \mathrm{mg}$ even for $20 \mathrm{~mm}$ in length.

For a given current, measurements of the erosion mass were performed more than four times. A new anode and a new cathode discs were mounted before every measurement to set the electrodes in the same condition. Fig. 3 represents the measured erosion masses $M_{\mathrm{a}}$ of the anode for the copper, silver and tungsten electrodes as a function of the peak value of the arc current. As shown in this figure, the erosion mass $M_{\mathrm{a}}$ of the anode for the copper electrodes increases from about 0.2 to $1.0 \mathrm{mg}$ with a rise in the peak value of the arc current from 500 to 1500 A. Similar rises in the erosion mass $M_{\mathrm{a}}$ were found for the silver and tungsten electrodes. For the silver electrode, the mass $M_{\mathrm{a}}$ varies from 0.05 to $0.4 \mathrm{mg}$ with an increase in the arc current from 350 to $1200 \mathrm{~A}_{\text {peak }}$. For

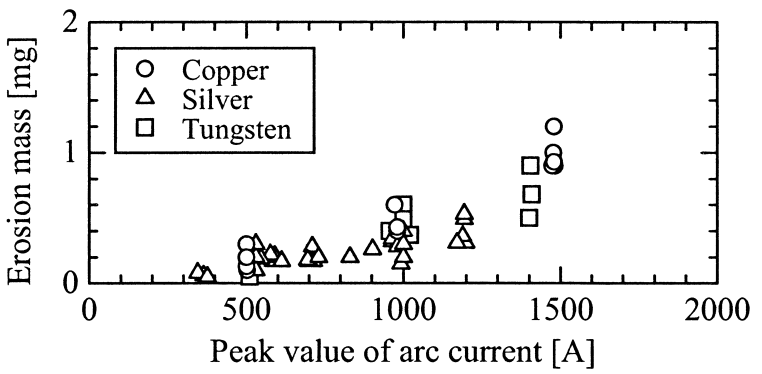

Fig. 3. Erosion mass of anode for copper, silver and tungsten electrodes

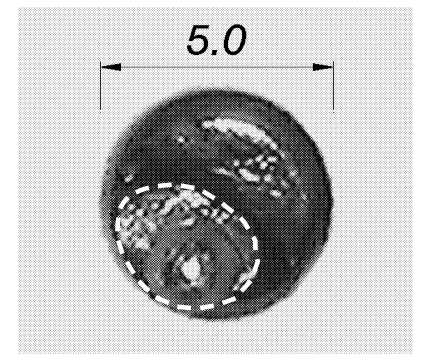

Fig. 4. Examples of copper anode surface after arc discharge in atmosphere for current of $1500 \mathrm{~A}_{\text {peak }}$

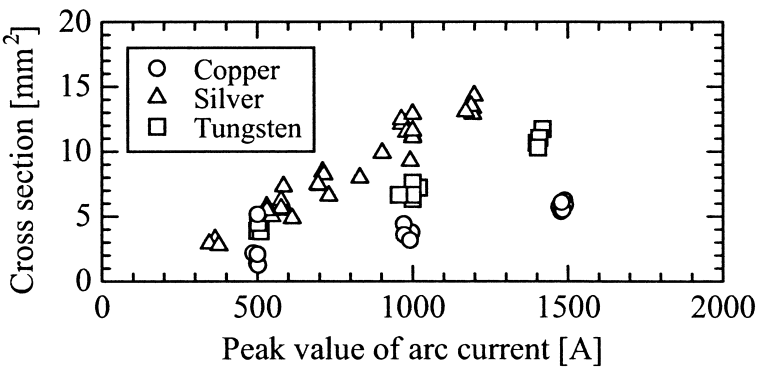

Fig. 5. Cross-section of anode spot for copper, silver and tungsten electrodes

the tungsten electrode, $M_{\mathrm{a}}$ is about $0.1 \mathrm{mg}$ at the current of $500 \mathrm{~A}_{\text {peak }}$ and reaches $0.5-0.9 \mathrm{mg}$ at $1400 \mathrm{~A}_{\text {peak }}$. In addition, no sputterd droplets caused by the arc discharge were observed for all electrode materials in the above current range.

2.3 Cross-section of Anode Spot In the next phase, the cross-section $S_{\mathrm{a}}$ of the anode spot was measured. After an arc discharge, the anode surface was observed by a digital camera. Fig. 4 shows a typical photograph of a copper anode surface after an arc establishment for an ac current with a peak value of $1500 \mathrm{~A}$. We regard the elliptic vestige of the ragged area on the anode surface resulting from an arc discharge, which is surrounded by the dashed line in Fig. 4, as the anode spot, because of the short duration of arc discharge and the motionlessness of the anode spot observed by a high-speed video camera with a recording rate of 13,500 frames/s. From the picture, the crosssection $S_{\mathrm{a}}$ was evaluated by visual observation. In the case of Fig. 4 , the cross-section $S_{\mathrm{a}}$ was measured to be $6.4 \mathrm{~mm}^{2}$.

Similarly, the cross-sections of the anode spot were measured for a given current ranging up to $1500 \mathrm{~A}_{\text {peak }}$ and for the copper, silver and tungsten electordes. 
Figure 5 indicates the obtained cross-section $S_{\mathrm{a}}$ as a function of the peak value of the arc current. The cross-section $S_{\mathrm{a}}$ for the copper anode was found to be about $2 \mathrm{~mm}^{2}$ at the current of $500 \mathrm{~A}_{\text {peak }}$ and reach about $6 \mathrm{~mm}^{2}$ at the current of $1500 \mathrm{~A}_{\text {peak }}$ with a rise in the peak value of the current. For the silver anode, $S_{\mathrm{a}}$ was also extended from about $3 \mathrm{~mm}^{2}$ to $14 \mathrm{~mm}^{2}$ with an increase in the arc current from 350 to $1200 \mathrm{~A}_{\text {peak }}$. For the tungsten anode, the cross-section $S_{\mathrm{a}}$ was found to vary from 4 to $11 \mathrm{~mm}^{2}$ with a rise in the current from 500 to $1400 \mathrm{~A}_{\text {peak }}$.

\section{Calculation of Energy Balance Equa- tions on Anode}

Concerning the silver, the previous paper have reported the method for determing the anode-fall voltage from $M_{\mathrm{a}}$ and $S_{\mathrm{a}}{ }^{(7)}$. The anode-fall voltage $V_{\mathrm{a}}$ for the copper and tungsten electrodes were derived in the similar way to that previously reported. The method will be described in the present chapter.

3.1 Expression for Temperature Distribution in Anode The temperature $T$ at the particular locations of the anode rises to the melting point $T_{\text {melt }}$ or up to the boiling point $T_{\text {boil }}$ of the anode material on account of the arc discharge. Thus the energy balance equations are given according to the temperature of the anode.

(1) $T<T_{\text {melt }} \quad$ In case that the temperature $T$ of the anode is lower than the melting point of the anode material, the heat conduction equation of the anode can be expressed by

$$
\rho C_{\mathrm{p}} \frac{\partial T}{\partial t}=\frac{\partial}{\partial z}\left(\kappa \frac{\partial T}{\partial z}\right)+\frac{1}{r} \frac{\partial}{\partial r}\left(\kappa r \frac{\partial T}{\partial r}\right) \cdots \cdots
$$

where $\rho$ is the density, $C_{\mathrm{p}}$ is the specific heat and $\kappa$ is the thermal conductivity of the anode material. In this equation, $r$ is a radial coordinate from the central axis of the anode and $z$ is a coordinate along the central axis of the anode respectively.

The boundary condition at the end surface of the anode, on which an arc is established, is expressed by

$$
-\left.\kappa \frac{\partial T}{\partial z}\right|_{z=0}=j_{\mathrm{a}}\left(V_{\mathrm{a}}+\phi\right)-W_{1} H_{\mathrm{evap}}-\varepsilon \sigma T^{4} \ldots
$$

where $H_{\text {evap }}$ is the heat of evaporation, $\varepsilon$ is the emissivity of the anode material, $\sigma$ is the Stefan-Boltzmann constant, $j_{\mathrm{a}}$ is the current density of the anode spot and $\phi$ is the work function of the anode material ${ }^{(9) \sim(11)}$. The quantity $V_{\mathrm{a}}$ is assumed to be independent of the instantaneous value of the arc current. On the right side in this equation, the first, the second and the third terms represent the energy input to the anode spot, the loss by evaporation and the loss by radiation respectively ${ }^{(3)(11)}$. The variable $W_{1}$ is the evaporation rate (the erosion mass per unit time and per unit area) which can be written in the following form ${ }^{(12)(13)}$ :

$$
W_{1}=10^{A-0.5 \log T-\frac{B}{T}}, \ldots \ldots \ldots \ldots \ldots \ldots \ldots
$$

where $A$ and $B$ are the constants and vary according to the electrode materials. The rate $W_{1}$ is very small and almost equal to zero when $T$ is low, e.g. below melting point.

On another end surface of the anode connected to the current supply circuit, the temperature $T$ is maintained at $300 \mathrm{~K}$, i.e., the ambient air temperature $T_{\infty}$ :

$$
\left.T\right|_{z=L_{\mathrm{a}}}=T_{\infty}
$$

where $L_{\mathrm{a}}$ is the length of the anode.

For the boundary condition at the lateral surface of the anode, the evaporation, the radiation and the natural convective heat transfer are taken into consideration. The boundary condition is represented by

$$
-\left.\kappa \frac{\partial T}{\partial r}\right|_{r=R_{\mathrm{a}}} ^{=} W_{1} H_{\text {evap }}+\varepsilon \sigma T^{4}+h\left(T-T_{\infty}\right) \cdots
$$

where $R_{\mathrm{a}}\left(=2.50 \times 10^{-3} \mathrm{~m}\right)$ is the radius of the anode and $h$ is the heat transfer coefficient.

The boundary condition along the central axis of the anode is expressed by

$$
\left.\frac{\partial T}{\partial r}\right|_{r=0}=0 . \cdots \cdots \cdots \cdots \cdots \cdots \cdots \cdots \cdots \cdots \cdots
$$

(2) $T=T_{\text {melt }} \quad$ When the temperature $T$ of the anode equals the melting point of the anode metal, the heat conduction of the anode is given by the following expression:

$$
W_{2} H_{\text {melt }}=\frac{\partial}{\partial z}\left(\kappa \frac{\partial T}{\partial z}\right)+\frac{1}{r} \frac{\partial}{\partial r}\left(\kappa r \frac{\partial T}{\partial r}\right), \cdots
$$

where $W_{2}$ is the meltrate per unit volume (the mass of molten material per unit time per unit volume) and $H_{\text {melt }}$ is the heat of fusion. Accordingly, the term $W_{2} H_{\text {melt }}$ is the energy consumed only by the phase change of metal melting on anode per unit volume and per unit time.

For the boundary conditions at the end and side surfaces, Eqs. (2), (4) and (5) are used on occasions that $T$ equals the melting temperature of the anode.

(3) $T_{\text {melt }}<T<T_{\text {boil }} \quad$ In the case that the temperature of the anode is higher than the melting point and lower than the boiling point of the anode material, Eqs. (1) (6) are used as the energy balance equations.

(4) $T=T_{\text {boil }} \quad$ When the temperature $T$ of the anode reaches the boiling point of the anode metal, the heat conduction of the anode can be expressed as follows:

$$
W_{3} H_{\text {evap }}=\frac{\partial}{\partial z}\left(\kappa \frac{\partial T}{\partial z}\right)+\frac{1}{r} \frac{\partial}{\partial r}\left(\kappa r \frac{\partial T}{\partial r}\right), \cdots
$$

where $W_{3}$ is the erosion mass (the mass of vaporized material) per unit time and per unit volume. From this equation, the erosion mass by evaporation is determined.

The boundary condition at the end surface of the anode for Eq. (8) is written by

$$
-\left.\kappa \frac{\partial T}{\partial z}\right|_{z=0}=j_{\mathrm{a}}\left(V_{\mathrm{a}}+\phi\right)-\varepsilon \sigma T^{4} . \cdots \cdots \ldots \ldots
$$

In this equation, the terms of the input to the anode spot and the loss by radiation were taken into account 
since the evaporation was considered in Eq. (8).

For the boundary condition at the side surface, the following equation is used on occasions that $T$ is equal to the boiling point of the anode material:

$$
-\left.\kappa \frac{\partial T}{\partial r}\right|_{r=R_{\mathrm{a}}}=\varepsilon \sigma T^{4}+h\left(T-T_{\infty}\right) . \cdots \cdots \cdots
$$

3.2 Current Density The current density $j_{\mathrm{a}}$ in Eqs. (2) and (9) has the radial profile of a parabolic distribution ${ }^{(14)}$. In our experiment, we provided a half cycle of the sinusoidal current

$$
i(t)=I_{\text {peak }} \sin (2 \pi f t)
$$

to the arc device. Thus, for the calculation of the energy balance equations, $j_{\mathrm{a}}$ is expressed as functions of radius and time, as follows.

The cross-section of the anode spot is assumed to vary proportionally with the instantaneous value of the arc current $i(t)$, then the instantaneous cross-section $s_{\mathrm{a}}(t)$ of the anode spot can be represented by

$$
s_{\mathrm{a}}(t)=S_{\mathrm{a}} \sin (2 \pi f t),
$$

where $f$ is the frequency of the current, and the measured cross-section $S_{\mathrm{a}}$ is regarded as that of the anode spot at the peak current $I_{\text {peak }}$ in the experiments described in Chapter 2. When the anode spot is replaced with the equivalent circle having the same cross-section, the equivalent radius $r_{\mathrm{a}}(t)$ can be given by

$$
r_{\mathrm{a}}(t)=\sqrt{\frac{s_{\mathrm{a}}(t)}{\pi}}=\sqrt{\frac{S_{\mathrm{a}} \sin (2 \pi f t)}{\pi}} \ldots \ldots \ldots \ldots
$$

Therefore the current density $j_{\mathrm{a}}$ on the anode surface, having a radial profile, at the time of $t$ can be written in the following form:

$$
j_{\mathrm{a}}(r, t)=\frac{2 I_{\text {peak }}}{S_{\mathrm{a}}}\left[1-\left(\frac{r}{r_{\mathrm{a}}(t)}\right)^{2}\right] \ldots \ldots \ldots \ldots
$$

3.3 Erosion Mass For the surface and for the internal space of the anode, $W_{1}$ and $W_{3}$ can be integrated respectively. The erosion mass of the anode per unit time $M_{\mathrm{a}}^{\prime}$ is given by the following form:

$$
\begin{aligned}
M_{\mathrm{a}}^{\prime}= & \int_{0}^{R_{\mathrm{a}}} W_{1} 2 \pi r d r+2 \pi R_{\mathrm{a}} \int_{0}^{L_{\mathrm{a}}} W_{1} d z \\
& +\int_{0}^{L_{\mathrm{a}}} \int_{0}^{R_{\mathrm{a}}} W_{3} 2 \pi r d r d z . \cdots \ldots \ldots
\end{aligned}
$$

Moreover, the time integral of the erosion mass $M_{\mathrm{a}}^{\prime}$ per unit time enables us to obtain the erosion mass $M_{\mathrm{a}}$ of the anode as the following expression:

$$
M_{\mathrm{a}}=\int_{0}^{30 \times 10^{-3}} M_{\mathrm{a}}^{\prime} d t
$$

In this equation, we define the integral time from 0 to $30 \mathrm{~ms}$. As shown in Fig. 2, the conducting period of the

\begin{tabular}{|c|c|c|c|c|}
\hline Material & $\mathrm{Cu}$ & $\mathrm{Ag}$ & W & Ref. \\
\hline Atomic mass $M$ & 63.55 & 107.87 & 183.85 & \\
\hline Density $\rho\left[\mathrm{kg} / \mathrm{m}^{3}\right]$ & 8920 & 10500 & 19350 & (15) \\
\hline $\begin{array}{l}\text { Specific heat } \\
C_{p}[\mathrm{~J} /(\mathrm{kg} \cdot \mathrm{K})]\end{array}$ & Refer & to figl & ure 6 . & (16) (17) \\
\hline $\begin{array}{l}\text { Thermal conductivity } \\
\kappa[\mathrm{W} /(\mathrm{m} \cdot \mathrm{K})]\end{array}$ & 401 & 429 & 173 & $(15$ \\
\hline Melting point $T_{\text {melt }}[\mathrm{K}]$ & 1358 & 1235 & 3680 & (15) \\
\hline Boiling point $T_{\text {boil }}[\mathrm{K}]$ & 2855 & 2437 & 5936 & (15) \\
\hline $\begin{array}{l}\text { Heat of fusion } \\
H_{\text {melt }}[\mathrm{kJ} / \mathrm{kg}]\end{array}$ & 206 & 102 & 190 & $(20)$ \\
\hline $\begin{array}{l}\text { Heat of evaporation } \\
H_{\text {evap }}[\mathrm{kJ} / \mathrm{kg}]\end{array}$ & 4815 & 2365 & 4348 & (20) \\
\hline Emissivity $\varepsilon$ & 0.02 & 0.02 & 0.20 & $(21)$ \\
\hline Work function $\phi[\mathrm{eV}]$ & 4.5 & 4.3 & 4.5 & $(22)$ \\
\hline$A$ (in equation (3)) & 9.30 & 9.17 & 10.3 & (12) \\
\hline$B$ (in equation (3)) & 16457 & 13582 & 40611 & (12) (13) \\
\hline $\begin{array}{l}\text { Heat transfer coeffi- } \\
\text { cient } h\left[\mathrm{~W} /\left(\mathrm{m}^{2} \cdot \mathrm{K}\right)\right]\end{array}$ & $\operatorname{Re}$ & to $\mathrm{fi}$ & 7. & (23) \\
\hline
\end{tabular}
arc current $t_{\text {arc }}$ is $10 \mathrm{~ms}$. Therefore, the above integral time is $20 \mathrm{~ms}$ longer than $t_{\text {arc }}$. Since the temperature of the anode at the time of $30 \mathrm{~ms}$ seems much lower than the temperature before current zero, it is assumed no erosion of the anode is caused at the time of $30 \mathrm{~ms}$.
Table 1. Representative values of physical properties of anode material and related data

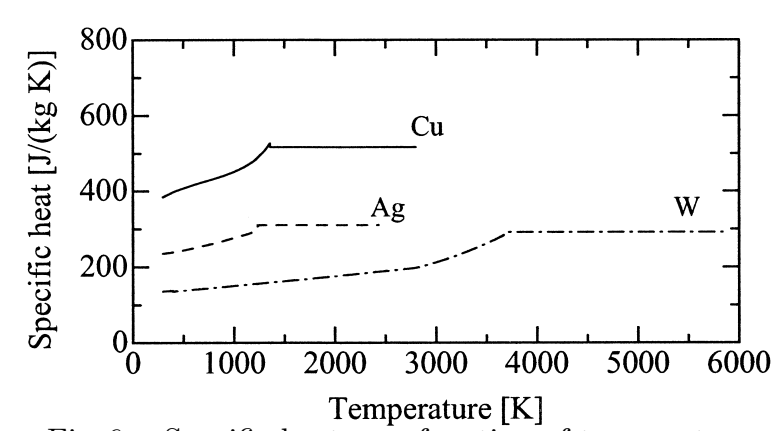

Fig. 6. Specific heat as a function of temperature

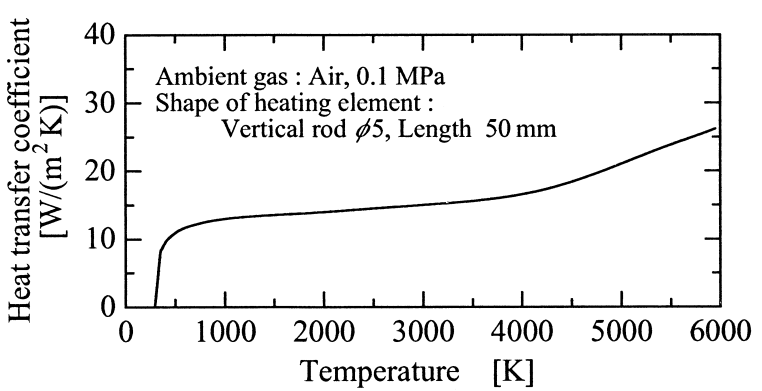

Fig. 7. Heat transfer coefficient of natural convection for vertical rod of diameter $5 \mathrm{~mm}$ and length $50 \mathrm{~mm}$ in atmosphere as a function of temperature

3.4 Result of Calculation Table 1 and Figs. 6 and 7 show the representative values of physical properties of the anode materials used for the numerical calculation of the energy balance equations. In this table, thermal conductivity $\kappa$ is regarded as constant value since temperature variations in thermal conductivity of pure copper and silver are very small for medium and high temperatures ${ }^{(18)}$. For the tungsten, thermal conductivity $\kappa$ is set to become gradually lower from $180 \mathrm{~W} /(\mathrm{m} \cdot \mathrm{K})$ at $300 \mathrm{~K}$ to $92 \mathrm{~W} /(\mathrm{m} \cdot \mathrm{K})$ at $3000 \mathrm{~K}$ and to $80 \mathrm{~W} /(\mathrm{m} \cdot \mathrm{K})$ at $5936 \mathrm{~K}^{(18)(19)}$. We numerically solved the above Eqs. $(1) \sim(10),(12) \sim(15)$ for temporary values of $V_{\mathrm{a}}$ and $S_{\mathrm{a}}$ for a given value of the current.

Figure 8 shows typical examples of the time variations in (a) the given arc current, (b) the temperature at the center of the anode surface and (c) the erosion 

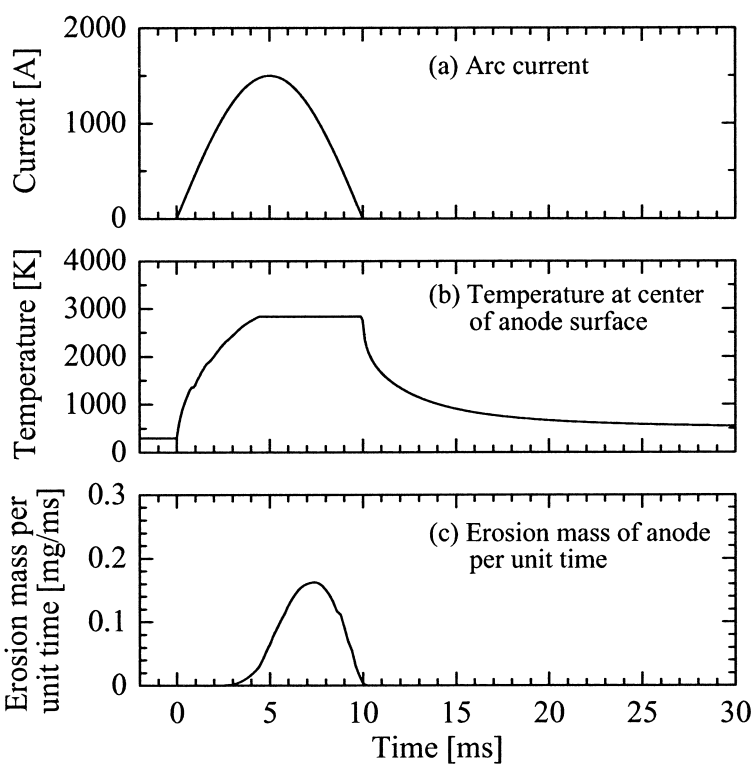

Fig. 8. Time variations in arc current, temperature of copper anode surface and erosion mass of copper anode per unit time for ac current of $1500 \mathrm{~A}_{\text {peak }}$, cross-section $S_{\mathrm{a}}$ of $7.0 \mathrm{~mm}^{2}$ and anode-fall voltage $V_{\text {a }}$ of $1.0 \mathrm{~V}$

mass of the anode per unit time for the copper anode. These waveforms were obtained on the conditions of an ac current of $1500 \mathrm{~A}_{\text {peak }}$ with a frequency of $50 \mathrm{~Hz}, S_{\text {a }}$ of $7.0 \mathrm{~mm}^{2}$ and $V_{\mathrm{a}}$ of $1.0 \mathrm{~V}$.

With a rise in the arc current $i$, the temperature $T$ of anode surface is increasing. The anode metal starts to be eroded at the time $t=3.0 \mathrm{~ms}, i=1200 \mathrm{~A}$ and $T=2500 \mathrm{~K}$. The temperature $T$ reaches $T_{\text {boil }}$ at the time of $4.5 \mathrm{~ms}$. The erosion of the anode is observed until the current zero point, during $T=T_{\text {boil }}$. Subsequently, the anode temperature begins to drop drastically at the time of the current zero, and no erosion is found after the current zero point.

In the case of Fig. $8, M_{\mathrm{a}}$ was calculated to be $0.62 \mathrm{mg}$ from $M_{\mathrm{a}}^{\prime}$ shown in Fig. 8 using Eq. (15).

In the same way, the numerical analyses were carried out in order to derive the erosion mass of the copper anode $M_{\mathrm{a}}$ for various pairs of anode-fall voltages $V_{\mathrm{a}}$ and cross sectional areas $S_{\mathrm{a}}$. The solid lines shown in Fig. 4.1 indicate the derived $M_{\mathrm{a}}$ for an arc current of $1500 \mathrm{~A}_{\text {peak }}$. The use of this figure enables us to estimate the anodefall voltage $V_{\mathrm{a}}$ as explained in next section.

\section{Anode-fall Voltage of Air Arc in Atmosphere}

4.1 Estimation of Anode-fall Voltage As described in Chapter 2, the erosion mass $M_{\mathrm{a}}$ of the anode and the cross sectional area $S_{\mathrm{a}}$ of the anode spot were measured. On the condition of the arc current with a peak value of $1500 \mathrm{~A}$, a filled circle marked with " $\mathrm{A}$ " is plotted in Fig. 4.1 at the position corresponding to the measured $M_{\mathrm{a}}$ of $0.93 \mathrm{mg}$ and $S_{\mathrm{a}}$ of $6.4 \mathrm{~mm}^{2}$. The positional relation between the plotted datum "A" and the theoretical curves enables us to estimate the anode-fall voltage at approximately $1.1 \mathrm{~V}$ for the air arc between copper electrodes.

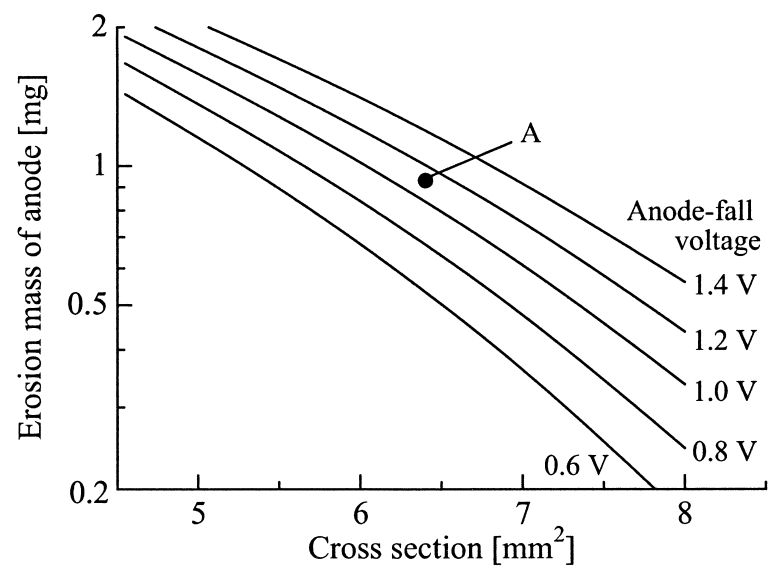

Fig. 9. Theoretical curves of erosion mass of copper anode as a function of cross-section of anode spot for arc current of $1500 \mathrm{~A}_{\text {peak. }}$. Anode-fall voltage for copper electrode is taken as a parameter

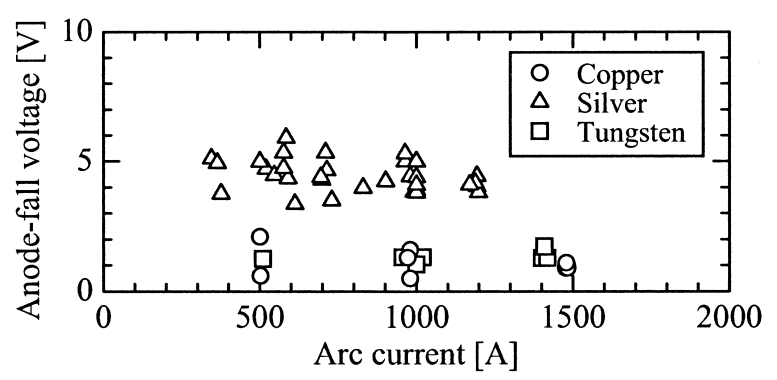

Fig. 10. Estimated anode-fall voltages for copper, silver and tungsten electrodes as a function of peak value of arc current

4.2 Anode-fall Voltage at Currrents Up to 1500 A Similar procedures were made to derive theoretical curves of the erosion mass $M_{\mathrm{a}}$ as functions of the cross-section $S_{\mathrm{a}}$ and the anode-fall $V_{\mathrm{a}}$ for different peak values of the current in the range of 500 to $1500 \mathrm{~A}$. Figure 4.1 shows the derived anode-fall $V_{\mathrm{a}}$ as a function of the peak value of the arc current. As seen in this figure, the anode-fall voltage $V_{\mathrm{a}}$ of an air arc between copper electrodes is found to be about $1.2 \mathrm{~V}$ and almost independent of the arc current in the above range.

In the same way, $V_{\mathrm{a}}$ for the silver and tungsten electrodes were determined. In Fig. 4.1, the anode-fall voltages of air arcs in atmosphere for the silver and tungsten electrodes are also represented as a function of the peak value of the arc current in addition to the copper electrode. From this figure, the following features are pointed out.

(1) For the silver, the deduced anode-fall voltage is found to be almost constant in a wide range from $350 \mathrm{~A}_{\text {peak }}$ up to $1200 \mathrm{~A}_{\text {peak }}$. The voltage $V_{\text {a }}$ for the tungsten electrode also prove to have the independency of the arc current ranging up to $1400 \mathrm{~A}_{\text {peak }}$ as found for the copper.

(2) For the silver electrode, the averaged anode-fall voltage $V_{\mathrm{a}}$ is estimated to be $4.5 \mathrm{~V}$, which is $3.3 \mathrm{~V}$ higher than that for the copper electrode.

(3) The averaged anode-fall voltage $V_{\mathrm{a}}$ for the tungsten electrode is derived to be about $1.2 \mathrm{~V}$. This voltage is as almost high as that for the copper electrode and $3.3 \mathrm{~V}$ lower than the averaged $V_{\mathrm{a}}$ for the silver electrode. 
(4) From the above results, it is also found that the difference in the anode material may vary the anode-fall voltage.

(5) With reference to other reserch reports, for copper electrode, the voltage $V_{\mathrm{a}}$ of argon arc was obtained to be about $5 \mathrm{~V}$ for dc current of $10 \mathrm{~A}$ by Dickson and Engel ${ }^{(2)}$, which is $3.8 \mathrm{~V}$ higher than that derived by our method. For tungsten electrode, Ando ${ }^{(24)}$ proved the anode-fall $V_{\mathrm{a}}$ of dc argon arc to be about $3.1 \mathrm{~V}$ in the current range from 30 to $100 \mathrm{~A}$. This voltage is $1.9 \mathrm{~V}$ larger than that estimated by our method, however the similar independency of the arc current was found.

(6) As written in Section 3.1, it was assumed that the voltage $V_{\mathrm{a}}$ is independent of the time variation in the arc current $i$ during the conducting period. The obtained anode-fall voltage $V_{\mathrm{a}}$ in this section has almost constant value for various peak values of the current ranging up to $1500 \mathrm{~A}$ for the copper, silver and tungsten. Therefore, the self-contradiction did not appear between the assumption and the result of the measurment. In addition, the independency of $V_{\mathrm{a}}$ in the arc current was also found in the report ${ }^{(24)}$ for various values of dc current. Thus, these facts indicates the assumption seemed to be valid.

\section{Conclusion}

A method for estimating the anode-fall voltage of an arc discharge was developed and the anode-fall voltages of air arcs in atmosphere for the electrodes of copper, silver and tungsten were measured in a current range up to $1500 \mathrm{~A}$ by using the method. The obtained anode-fall voltages for these materials proved to have the constant value and to be almost independent of the arc current in the range above. The anode-fall voltage $V_{\mathrm{a}}$ for the copper electrode was found to be about $1.2 \mathrm{~V}$ which was 3.3 $\mathrm{V}$ lower than that for the silver electrode and as high as that for the tungsten electrode. Consequently, the dissimilarity in the anode material seems to lead to the variation in the anode-fall voltage $V_{\mathrm{a}}$.

This work was partly supported by the Grant-in-Aid for Scientific Research (B)(2)13555080 from the Ministry of Education, Culture, Sports, Science and Technology, Japan.

(Manuscript received Feb. 26, 2003, revised July 9, 2003)

\section{References}

(1) V.A. Nemchinsky: "Plasma parameters near a small anode in a high-pressure arc (gas metal arc welding)", J. Phys. D: Appl. Phys., Vol.27, pp.2515-2521 (1994)

(2) D.J. Dickson and A. von Engel: "Resolving the electrode fall spaces of electric arcs", Proc. Roy. Soc. A, Vol.27, pp.316-325 (1967)

(3) R. Hajossy and I. Morva: "Cathode and anode falls of arcs with fusible electrodes", J. Phys. D: Appl. Phys., Vol.27, pp.2095-2101 (1994)

(4) I.G. Kesaev: "Laws governing the cathode drop and the threshold currents in an arc discharge on pure metals", Sov. Phys.—Tech. Phys., Vol.9, pp.1146-1154 (1965)

(5) D.J. Hamilton and A.E. Guile: "Ionization in the cathodefall region of moving arcs", Brit. J. Appl. Phys., Vol.1, pp.335-342 (1968)

(6) A. von Engel: Ionized Gases, pp.273-276, Clarendon, Oxford (1965)

(7) R. Hemmi, W. Honda, Y. Yokomizu, and T. Matsumura: "Anode-fall and cathode-fall voltages of air arc between $\mathrm{Ag}$ electrodes at a pressure of 0.1 MPa", The Papers of Joint Technical Meeting on Electrical Discharges, Switching and Protecting Engineering and Frontier Technology and Engineering, IEE Japan, ED-02-37/SP-02-3/FTE-02-9, pp.11-15 (2002) (in Japanese)

(8) R. Hemmi, Y. Yokomizu, and T. Matsumura: "An Investigation of Method for Estimating Anode-fall and Cathode-fall voltages of High Current Arc", Proc. of the 14th Annual Conf. of Power \& Energy Society, IEE Japan, Vol.B, No.232, pp.133134 (2003) (in Japanese)

(9) J.D. Cobine and E.E. Burger: "Analysis of electrode phenomena in the high-current arc", J. Appl. Phys., Vol.26, pp.895900 (1955)

(10) M. Sugawara: "Anode melting caused by a d.c. arc discharge and its application to the determination of the anode fall", Brit. J. Appl. Phys., Vol.18, pp.1177-1181 (1967)

(11) W. Rieder: "Leistungsbilanz der Elektroden und Charakteristiken frei brennender Niederstrombögen", Z. Phys., Vol.146, pp.629-643 (1956) (in German)

(12) S. Dushman: Scientific Foundations of Vacuum Technique, 2nd ed., pp.691-703, John Wiley \& Sons, Inc., New York (1979)

(13) T. Nishikawa, S. Nakajima, and K. Kikuchi: Butsurigaku Jiten (Physics Dictionary), p.2330, Baifukan, Tokyo (1986) (in Japanese)

(14) K.C. Hsu, K. Etemadi, and E. Pfender: "Study of the free-burning high-intensity argon arc", J. Appl. Phys., Vol.54, pp.1293-1301 (1983)

(15) J.A. Dean: Handbook of Chemistry, 12th ed., McGraw-Hill, New York (1979)

(16) Y.S. Touloukian and E.H. Buyco: Thermophysical Properties of Matter Vol.4, Specific Heat-Metallic Elements and Alloys, IFI/Plenum, New York (1970)

(17) I. Barin: Thermochemical Data of Pure Substances Part I, 2nd ed., VCH, New York (1993)

(18) R. Holm: Electric contacts, 4th ed., pp.395-396, SpringerVerlag, New York (1967)

(19) O. Madelung and G.K. White: Landolt-Börnstein: Numerica Data and Functional Relationships in Science and Technology, New Series, Group III: Crystal and Solid State Physics, Vol.15c Metals: Electronic Transport Phenomena-Thermal Conductivity of Pure Metals and Alloys, Springer-Verlag, Berlin (1991)

(20) S. Allard: International Tables of Selected Constants Vol.16, Metals: Thermal and Mechanical Data, Pergamon Press, Oxford (1969)

(21) Y.S. Touloukian and D.P. DeWitt: Thermophysical Properties of Matter Vol.7, Thermal Radiative Properties-Metallic Elements and Alloys, IFI/Plenum, New York (1970)

(22) D.E. Gray: American Institute of Physics Handbook, 3rd ed., McGraw-Hill, New York (1972)

(23) W.H. McAdams: Heat Transmission, 3rd ed., pp.165-183, McGraw-Hill, New York (1954)

(24) H. Ando and M. Hasegawa: Yousetsu Arc Gensho (Arc phenomena in Welding), Enlarged ed., p.120, Sanpo, Tokyo (1967) (in Japanese)

Rei Hemmi (Member) received the M.S. degree in electrical

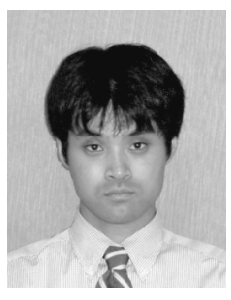
engineering from Nagoya University of Japan in 1996. From 1996 to 2001, he worked for Hitachi, Ltd., and was mainly in charge of GIS design engineering. Since 2002, he has been a Ph.D. course student of Nagoya University at the Department of Electrical Engineering, the Graduate School of Engineering. Currently, he is involved in the study of the electrode phenomena of high current arc. 
Yasunobu Yokomizu (Member) received the Ph.D. degree in electrical engineering from Nagoya University of Japan in 1991. He was an Assistant Professor of Nagoya University from 1990 to 1997. He was a Visiting Fellow in the University of Liverpool, UK from 1997 to 1998. Currently, he has been an Associate Professor in the Department of Electrical Engineering at Nagoya University since 1997 . He was also an Associate Professor at the Center for Integrated Research in Science and Engineering of Nagoya University from 1998 to 2002. Presently, he is in charge of the researches on high current arc physics and environment-benign energy system. $\mathrm{He}$ is a member of IEEE.
Toshiro Matsumura (Member) received the Ph.D. degree

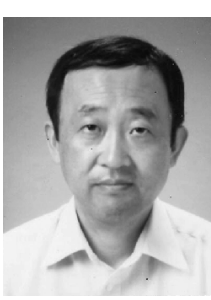
in electrical engineering from Nagoya University of Japan in 1980. He was an Assistant Professor from 1979 to 1987 and an Associate Professor from 1987 to 1989 and from 1992 to 1995 of Nagoya University. He was a Visiting Researcher at the University of Sydney of Australia from 1984 to 1985. He was an Associate Professor of Kyoto University of Japan form 1989 to 1991. Currently, he has been a Professor in the Department of Electrical Engineering at Nagoya University since 1995. He is recently interested in the researches on high current arc interruption phenomena, theory and application of high temperature plasmas and effective utilization of electrical energy. He is a member of IEEE. 